\title{
Electrical Safety and Stray Current Protection with Platform Screen Doors in DC Rapid Transit
}

\author{
Andrea Mariscotti, Senior Member, IEEE
}

\begin{abstract}
Modern transit system are equipped with platform screen doors (PSDs) that represent a new element introduced in the electrical safety and stray current protection scenarios. Passengers may interact with PSDs and platform while boarding, leaving and waiting trains. Typical contractual requirements and applicable standards are discussed, identifying touch voltage scenarios suitably defining electrical circuits and parameters. DC voltage limits are at all clear and unambiguous in the range of relevant touch voltage values. The evaluation of exposure is thus carried out with the help of body impedance and body current models. Solutions are then discussed for protection of PSDs and passengers, including stray current limitation as constraint. A novel PSD bonding arrangement is proposed that reconciles insulation for utmost electrical safety level and bonding for traction fault protection.
\end{abstract}

Index Terms-Electrical safety; Guideway transportation system; Stray Current; Touch Voltage; Traction power supplies

\section{INTRODUCTION}

$\mathrm{M}$ ODERN electrified railways and rapid transit systems feature more and more often platform passenger protection barriers or doors that prevent direct access to the track from the platform area. The first installation dates back to 1987 (Singapore Mass Rapid Transit), but the pace has increased in the last twenty years, starting from the first realization in China (Guangzhou's Metro Line 2), where now these devices are compulsory. Products and realizations may be classified as Platform Safety Gates (PSGs, half height, typ. about $1.5 \mathrm{~m}$ ), Platform Edge Doors (PEDs, full height, typ. taller than $2 \mathrm{~m}$ ), and Platform Screen Doors (PSDs, up to the ceiling of covered stations, allowing full separation of track area for protection against noise, dust, and optimization of station ventilation and air conditioning) [1]. PSDs in particular necessitate a robust supporting structure for the increased weight and the piston effect: in this case ensuring and preserving the electrical insulation from civil structures is an important point. All these barriers (in the following collectively named "PSDs") feature sliding doors housed in a metallic frame, anchored to the platform, laterally to walls, and to suspended civil structures. They are also often lined up with metallic cladding for durability and aesthetic reasons.

As a conductive element positioned between track, trains and platform and interacting with passengers, PSDs are quite relevant to electrical safety [2][3]. In addition, they are also a

A. Mariscotti is with the Department of Electrical, Electronic and Telecommunications Engineering, and Naval Architecture, University of Genoa, Genoa, 16145 Italy. potential stray current leaking path at platform. Depending on the traction return circuit arrangement, line loading, system aging and environmental conditions, various degrees of touch voltage exposure and stray current leakage may occur. The various conductive parts (PSD frame, platform floor and walls, other equipment and metal works) may be subjected to technical solutions (electrical insulation, bonding to specific potential, etc.) to achieve compliance to standards [4]-[6] and contractual specifications [7]-[9].

Assessment of touch voltage compliance is usually considered with worst-case assumptions that, if not properly evaluated in terms of likeliness and concomitance, lead to oversizing. Similarly, standard limits and requirements may be misinterpreted, in an exaggeratedly precautionary perspective. Traction fault current is part of earthing network design and selection of protections [10][11]. Track voltage information instead can be derived during design from traction power simulations, with various levels accuracy for line exploitation, train performance, dynamic power allocation and traction power stations (TPSs) outages [12][13]. Assumptions and simulations are thus relevant as electrical safety and stray current protection must be ensured by design, with experimental results seen as validation.

This work wants to consider the problem from all sides. Sec. II discusses normative and contractual requirements for stray current and electrical safety, with emphasis on the latter and the complex problem of defining suitable low-voltage dc touch voltage limits. Sec. III focuses on simulation approaches to derive track voltage values used as input for electrical safety assessment at design stage, suitably including worst-case configurations. Sec. IV then presents electrical safety scenarios and discusses design choices to ensure protection of staff and passengers for impermissible and uncomfortable touch voltages. The most common solution is that of imposing platform insulation with PSD bonded to the track, but alternative solutions are explored, including a novel arrangement of PSD bonding. Fig. 1 contains a general sketch of the platform area, PSDs and a typical track cross section, to use as reference throughout the discussion.

\section{REQUIREMENTS AND CONSTRAINTS}

The overall problem is divided into its main constituents for the discussion of requirements and specifications.

\section{A. Stray current protection}

Stray current protection for the track is disciplined almost exclusively by the IEC $62128-2$ [6], with a minimum track- 


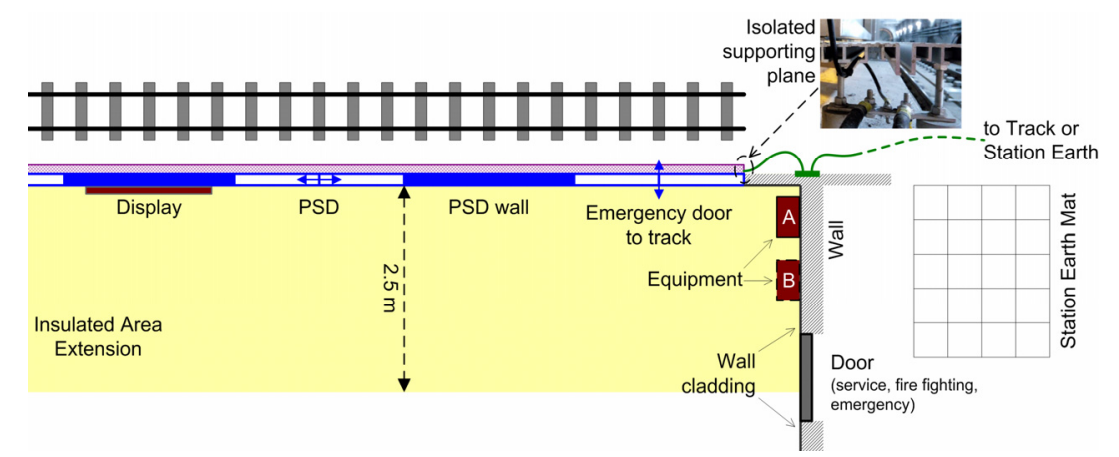

(a)

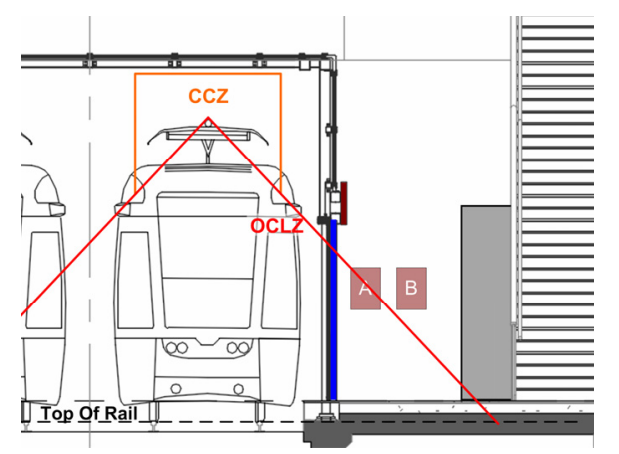

(b)

Fig. 1. Sketch of (a) elements relevant to electrical safety and stray current at platform, (b) line and platform cross section with CCZ (Current Collector Zone) and OCLZ (Overhead Contact Line Zone), as per IEC 62128-1 [4].

to-earth resistance $R_{t e}$ of $2 \Omega / \mathrm{km}$ (for track in open formation), consequential to a limit of track leakage current of $2.5 \mathrm{~mA} / \mathrm{m}$, having assumed an average positive track voltage $\left\langle V_{t e}^{+}\right\rangle \leq 5 \mathrm{~V}$ over $24 \mathrm{~h}$. High-performance transit systems, as well as those with increased traffic, will experience higher $\left\langle V_{t e}^{+}\right\rangle$values and correspondingly should be required higher track insulation. Contractual specifications have consistently shifted to more restrictive values, to ensure some margin on IEC 62128-2 limits throughout system life. Sec. III will consider $R_{t e}$ as one of the parameters to feed to traction power simulation.

Electrical insulation requirements for wayside installations, structures and metal works may vary depending on the overall approach to stray current protection. Insulation is in general preferable, provided that it is preserved throughout system service life. Conversely a lower level of insulation is acceptable between structural parts (track bed, tunnel sections, viaduct spans), if elements are single-point bonded to a parallel earth conductor, controlling the potential and avoiding stray current flow along parallel paths.

\section{B. Touch voltage and Body current}

\section{1) Touch voltage limits}

DC touch voltage limits may be found in IEC 62128-1 [4] for railway applications, in IEC 60364-4-41 [14] for Low Voltage (LV) installations, and in some other standards reviewed in the following. An interesting comparison of ac touch voltage limits of IEC and IEEE can be found in [15], whereas dc applications are in general poorly covered, in particular for the low voltage values that are of interest here. Step voltage for a passenger boarding or leaving the train has a higher limit and is not therefore considered further.

For transients (e.g. in case of fault) touch voltage limits are set in terms of amplitude-duration pairs [4]; only a few more restrictive values applicable to live parts appear in [5]. ANSI and IEEE do not give limits for dc voltages, but the IEEE Std. 1653.3 [16], Annex F, offers an overview of the track voltage limits at many light and heavy railway systems in the US.

There is a long debate about the danger represented by low voltage steady dc values: IEC/CENELEC and OSHA [17], sec. g.2.i, report two different values for the "safe voltage level", namely 60 and $50 \mathrm{Vdc}$, respectively, with significant responsibility in case of accidents for those $10 \mathrm{~V}$ in between [18]. More precisely, IEC 62128-1 and IEC 60364-4-41 indicate $120 \mathrm{Vdc}$ as a safe voltage level, either explicitly (the former) or by waiving requirements for the fault clearing time (the latter). A $60 \mathrm{Vdc}$ limit is assigned to workshops to protect against "uncontrolled reactions", but it is underlined that "injuries through the direct effect of electrical voltage and current are not expected." [4].

However, the IEC 61140 [19] (a basic safety publication, that is a reference for IEC technical committees) is of opposite opinion, indicating a $60 \mathrm{Vdc}$ limit as a necessary (but not sufficient) element for basic protection, only for dry conditions and small to medium area of contact. The IEC 61140 also indicates for dry conditions and $3500 \mathrm{~mm}^{2}$ of contact area (intermediate between medium and large areas of IEC 60479-1 [20]) 8 and $40 \mathrm{Vdc}$ as limit value for startle and muscular reaction. Although indicated as "touch voltages", they should be interpreted as "body voltages" in the sense of IEC 62128-1, so with the circuit not including external resistances (e.g. shoes, floor, etc.). Prescribed body current limits are 2 and $10 \mathrm{~mA}$ for normal and abnormal conditions, without a better description of the abnormal conditions (unlike scenarios, or of limited time duration, etc.).

It is noted that reported incidents used in favor of restrictive limits often include electrocution in confined spaces (e.g. welder sitting on metallic supports and electrocuted directly to chest) [21] and burns (typical incident caused by automobile batteries [22]), both not applicable to the present case.

2) Body current limits and body impedance

At the origin of touch voltage limits there is the objective of limiting the flow of current through the body under various assumptions. The IEC 60479-1 [20] establishes human body resistance values and maximum tolerated body current intensity, depending on the path within the body. The standard distinguishes various types of contact (large, medium and small surface areas of 10000, 1000 and 100 $\mathrm{mm}^{2}$; dry, water-wet and saltwater-wet body conditions) and reports statistics of body resistance. The applied pressure, distinguishing e.g. touching a surface from holding a handle, is not defined, but when testing insulation resistance of walls and ceilings a force of $250 \mathrm{~N}$ is required [4][23].

The characteristic levels of body current $I_{b}$ at dc are summarized as follows (IEC 60479-1, Fig. 22):

1. Zone DC-1: $I_{b} \leq 2 \mathrm{~mA}$ for any time duration; the 
physiological effects are described as "Slight pricking sensation possible when making, breaking or rapidly altering current flow."

2. Zone DC-2: $2 \mathrm{~mA}<I_{b} \leq 25 \mathrm{~mA}$ down to $2 \mathrm{~s}$, then 33 mA@1s,40mA@0.6s [24]; the physiological effects are described as "Involuntary muscular contractions likely especially when making, breaking or rapidly altering current flow, but usually no harmful electrical physiological effects."

The target limit for negligible effects is thus $I_{b 1}{ }^{*}=2 \mathrm{~mA}$, but larger intensity can be well tolerated, especially for short time intervals, so that $I_{b 2}{ }^{*}=25 \mathrm{~mA}$ should be also considered. In any case these current levels do not configure a hazard, but an uncomfortable or painful situation.

The current is in general of the anodic type (sec. 6.8 [20]): current enters the body from a source point of positive polarity (e.g. touching hand), exiting towards the earth potential (e.g. through the feet).

The body dc resistance $R_{b}$ [20] varies with applied voltage and is quite dispersed (the dispersion/mean ratio is about $0.55-0.65) . R_{b}$ values in Table I cover typical $V_{t e}$ values and refer to hand-to-hand current path for large surface; values for hand-to-foot path are $10 \%$ to $30 \%$ smaller. These values hold for a current flow of approximately $0.1 \mathrm{~s}$, above which values begin reducing by about $10-20 \%$, and more for longer times, approaching the initial body resistance value $R_{0}$. This value is taken as 500, 750 and $1000 \Omega$ for the $5 \%, 50 \%$ and $95 \%$ of the population, respectively. These dc values are all higher than the corresponding ac values thanks to the blocking effect of human skin capacitance. Extrapolated values were obtained using Matlab function pchip (shapepreserving piecewise cubic interpolation), that is superior to the linear interpolation used in sec. B.2.3.4 of IEC 60479-5, giving larger values.

For smaller contact surfaces the IEC 61479-1 does not report other $R_{b}$ dc values; ac values in Table 4 thru 9 of the standard for medium and small surface area in dry conditions are about 4-5 and 35-45 times higher than large surface case, respectively (for the $5 \%$-of-population column). Taking the large surface area values is thus conservative and cover cases of an entire palm pressed against a metallic surface (e.g. wall cladding, metallic handle or handrail, etc.).

TABLE I. TOTAL BODY RESISTANCE $R_{B}[\Omega]$ AT DC FOR HAND-TO-HAND PATH,

LARGE SURFACE AREA OF CONTACT, DRY CONDITIONS (IEC 60479-1); EXTRAPOLATED VALUES AT LOWER VOLTAGE (IN ITALIC)

\begin{tabular}{|c|c|c|c|}
\hline Touch voltage [V] & 5\% of pop. & $\mathbf{5 0 \%}$ of pop. & 95\% of pop. \\
\hline 0 & 2738 & 5123 & 9784 \\
\hline 10 & 2473 & 4606 & 8745 \\
\hline 25 & 2100 & 3875 & 7275 \\
\hline 50 & 1600 & 2900 & 5325 \\
\hline 75 & 1275 & 2275 & 4100 \\
\hline 100 & 1100 & 1900 & 3350 \\
\hline 125 & 975 & 1675 & 2875 \\
\hline 150 & 875 & 1475 & 2475 \\
\hline 175 & 825 & 1350 & 2225 \\
\hline 200 & 800 & 1275 & 2050 \\
\hline
\end{tabular}

\section{3) AC ripple superposed to DC voltage}

The track voltage is not purely $\mathrm{dc}$ and bears a small amount of ac ripple due to traction harmonics: this term is not calculated by traction power simulations, as it needs a specific harmonic load flow study. Substation ripple can be estimated considering the typical voltage distortion of 6- and 12-pulse rectifiers [25], sec. 8.2. Some factors contribute reducing track voltage harmonics: some substations are equipped with LC filters for dc, line harmonics flow through the onboard filter before going back to the TPS as return current, and the track has a low-pass behavior thanks to the increased series impedance [26] and conductance and capacitance to earth [27]-[29] (equivalent circuit shown in Fig. 2). The dc voltage ripple for harmonics of order 6 , assuming flat dc current, is:

$$
\begin{aligned}
& \frac{V_{d, h=6 n}}{V_{d 0}}=\left[\left(\frac{\cos ((h-1) \mu / 2)}{h-1}\right)^{2}+\left(\frac{\cos ((h+1) \mu / 2)}{h+1}\right)^{2}+\right. \\
& \left.-2\left(\frac{\cos ((h-1) \mu / 2)}{h-1}\right)\left(\frac{\cos ((h+1) \mu / 2)}{h+1}\right) \cos (2 \alpha+\mu)\right]^{\frac{1}{2}}
\end{aligned}
$$

where $\alpha$ is the firing angle (zero for a diode rectifier) and $\mu$ is the commutation overlap angle. The first 4 characteristic harmonics are calculated in Table II for $\mu$ up to $40^{\circ}$, covering thus power absorption levels up to overloading.

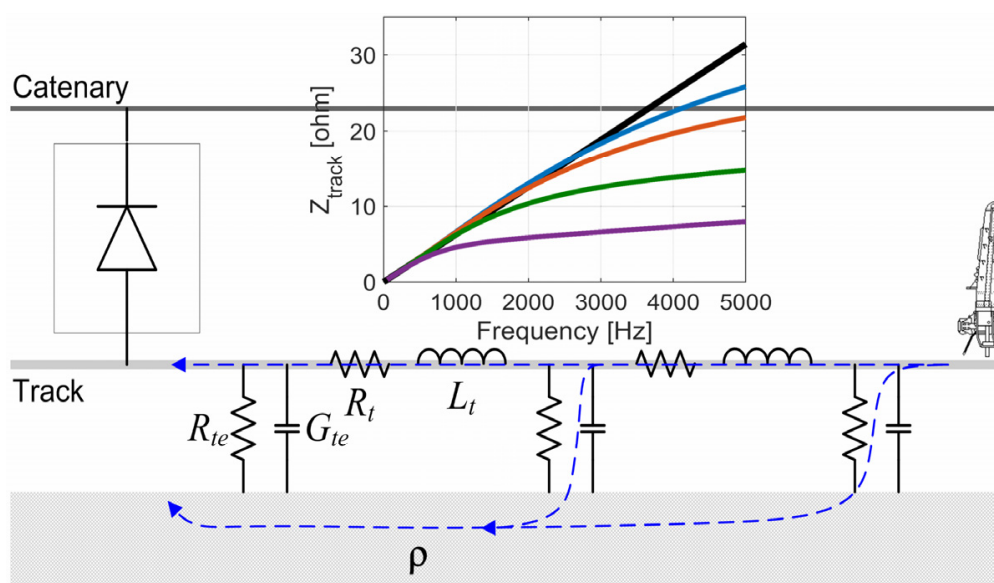

Fig. 2. Equivalent circuit of the track and traction return relevant to the quantification of the ac ripple of the track-to-earth voltage $V_{t e}$. The $Z_{\text {track }}$ values are calculated for $1 \mathrm{~km}$ of track and parametrized from bottom to top

\begin{tabular}{|c|c|c|c|c|c|c|}
\hline $\begin{array}{c}\text { Overlap angle } \\
\mu\left[{ }^{\circ}\right]\end{array}$ & $\begin{array}{c}\mathrm{V}_{6, \mathrm{rms}} \\
\%\end{array}$ & $\begin{array}{l}V_{12, \text { rms }} \\
\%\end{array}$ & $\begin{array}{l}\mathrm{V}_{18, \mathrm{rms}} \\
\quad \%\end{array}$ & $\begin{array}{l}\mathrm{V}_{24, \text { rms }} \\
\%\end{array}$ & $\begin{array}{c}\mathbf{V}_{\text {6tot,rms }} \\
\%\end{array}$ & $\begin{array}{c}\mathrm{V}_{12 \text { tot,rms }} \\
\%\end{array}$ \\
\hline 0 & 5.714 & 1.399 & 0.619 & 0.348 & 5.93 & 1.44 \\
\hline 5 & 6.071 & 1.698 & 0.853 & 0.522 & 6.38 & 1.78 \\
\hline 10 & 6.907 & 2.091 & 0.968 & 0.580 & 7.30 & 2.17 \\
\hline 15 & 7.799 & 2.172 & 1.172 & 1.133 & 8.26 & 2.45 \\
\hline 20 & 8.432 & 2.285 & 1.998 & 1.580 & 9.10 & 2.78 \\
\hline 25 & 8.674 & 3.101 & 2.680 & 1.615 & 9.73 & 3.50 \\
\hline 30 & 8.580 & 4.394 & 2.787 & 2.112 & 10.25 & 4.88 \\
\hline 35 & 8.405 & 5.497 & 2.898 & 2.545 & 10.76 & 6.06 \\
\hline 40 & 8.579 & 6.003 & 3.624 & 2.533 & 11.37 & 6.51 \\
\hline
\end{tabular}
on $R_{t e}=1,10,30,100$ and $300 \Omega \mathrm{km}$.

To include the effects of superposed ac ripple the IEC 60479-2 [30] and IEC 60990 [31] should be used, where the effects of ac components on perception, let-go and ventricular fibrillation are accounted for with frequency 
factor curves, synthesized in resistive-capacitive circuits combined with the unweighted human body circuit model.

For 12-pulse rectifiers commonly used in metros and light railways only the $\mathrm{V}_{12}$ and $\mathrm{V}_{24}$ terms in Table II would apply, and the total rms voltage $V_{\text {tot,rms,12 }}$ (rms summation of the harmonics) is slightly more than $6 \%$. For 6-pulse rectifiers instead the theoretical $V_{\text {tot,rms }, 6}$ is slightly above $10 \%$, but may be still considered a ripple-free situation with some approximation. Measured values are lower: $0.4-0.8 \%$ for a $3 \mathrm{kV}$ de railway (with LC filter at substation) and 1.3-1.5\% for a $1.5 \mathrm{kV}$ metro, based on recordings in [32] using intervals without transients and calculating the total rms as maximum every $1 \mathrm{~s}$ with a $10 \mathrm{~ms}$ sliding window. Line voltage ripple is thus not a relevant factor for electrical safety.

A new source has recently appeared with the introduction of reversible substations and use of forced-commutation converters: switching components of a few $\mathrm{kHz}$ leak in the return circuit as result of ground potential unbalance and conductive coupling; the observed intensity is up to a hundred $\mathrm{mA}$ with a track voltage ripple of some Vrms, so relevant only at the lowest $V_{t e}$ values, below $30 \mathrm{~V}$ or so.

\section{Earthing and bonding for electrical safety}

Protection of persons is achieved by a combination of provisions [4][14]: barriers and separation against direct contact, electrical insulation, and earthing for circuit interruption consequential to a fault or loss of insulation.

All conductive parts wayside that may get in contact with a falling catenary or a derailed pantograph and become live at traction voltage level shall be earthed [4]: two crosssectional areas named OCLZ (Overhead Contact Line Zone) and CCZ (Current Collector Zone) are defined to this aim (see Fig. 1). Earthing is achieved by bonding to the return circuit or station earth. The latter is discouraged in dc traction systems as it adversely affects stray current protection, but is not forbidden, provided that does not cause leakage in normal conditions (during transients electric safety takes precedence).

Exceptions are small conductive parts that have a lesser probability of being hit, combined with the possibility for a person approaching the part to see if they are in contact with a live traction conductor [4]. The PSD is evidently an extended conductive part that by construction does not allow this kind of check on the track side. For these reasons PSDs must be protected against traction fault by bonding: directly to the track (preferred) or to the station earth.

\section{Electrical insulation and protection by obstacle}

For live parts the IEC 62128-1 prescribes among others a protection by obstacle, to impede the direct contact. The PSDs are such an obstacle, saving passengers from a fall, incident with trains, but also accidental contact with the third rail.

Since PSDs in most designs are at the track potential and insulated from the station earth, for protection of passengers a prescription of electrical insulation is applied for floor, walls and other conductive parts in line with Annex C of [5].
What can be touched by passengers touching at the same time the train or the PSD must be electrically insulated (over the insulated area of exposure, IAE): in IEC 60364-4-41 [5] an insulated area extension is prescribed of $1.25 \mathrm{~m}$ for contact with feet and hand, and $2.5 \mathrm{~m}$ for both hands with stretched arms. Contractual prescriptions are not uniform, ranging in general between 2 and $2.5 \mathrm{~m}$, but rarely specify the corresponding insulation level. IEC 60364-4-41 requires $50 \mathrm{k} \Omega$ for a nominal voltage of the installation up to $500 \mathrm{~V}$, $100 \mathrm{k} \Omega$ above it.

The wording "nominal voltage" gives rise to a controversy, because nominal voltage is a concept applicable to live parts, but running rails (and parts connected to them) are excluded by the IEC 62128-1, sec. 3.1.13. They have a working voltage due to the longitudinal voltage drop, but not a nominal voltage. So, if they do not fall automatically in the IEC 60364-4-41 categories, the necessary platform insulation level must be determined to limit the current through the body.

\section{E. Reworked touch voltage and insulation limits}

So far we have identified touch voltage and surface insulation limits for live circuits, the tolerated body current values, and the body impedance models. For PSD and track as conductive parts a touch voltage limit is needed that guarantees passengers' comfort below $I_{b 1}{ }^{*}$ and $I_{b 2}{ }^{*}$.

A passenger standing on the platform and touching a conductive part at $V_{t e}$ will see a $I_{b}$ value given by:

$$
I_{b}=\frac{V_{t e}}{R_{b}\left(V_{t e}, t\right)+R_{s h}+R_{f w}}
$$

where $R_{b}$ is indicated as time varying and a function of $V_{t e}$, $R_{s h}$ and $R_{f w}$ are the shoes and floor (or wall) resistance.

If the person touches two conductive parts with the difference of potential $V_{t e}$ (so a hand-to-hand scenario), the new current $I_{b}$ is given by (2), having reduced $R_{b}$ by $20 \%$ (average of 10 to $30 \%$ ) as explained in sec. II.B-2).

Calculated $I_{b}$ curves are shown in Fig. 3 vs. $V_{t e}$, assuming a duration between one and some seconds, larger than the threshold of $0.7 \mathrm{~s}$ for long-term phenomena indicated by IEC $62128-1$, sec. D.3.3, and applying a reduction of $20 \%$ to $R_{b}$. Some external resistive components are also taken into account for the hand-to-feet scenario: $R_{s h}=1 \mathrm{k} \Omega$ and $R_{f w}=0$, 2, 5, 10 and $50 \mathrm{k} \Omega$ (labeled as floor0, 1, 2, 3 and 4). The hand-to-feet configuration with its lower resistance is relevant for ventricular fibrillation, situation from which we are quite far in the present case. Conversely for let-go assessment the most relevant is the hand-to-hand (IEC $62128-1$, App. D), that has a larger body resistance $(133 \%$ or $1 / 0.75)$. In addition the external resistive components cannot be invoked. 


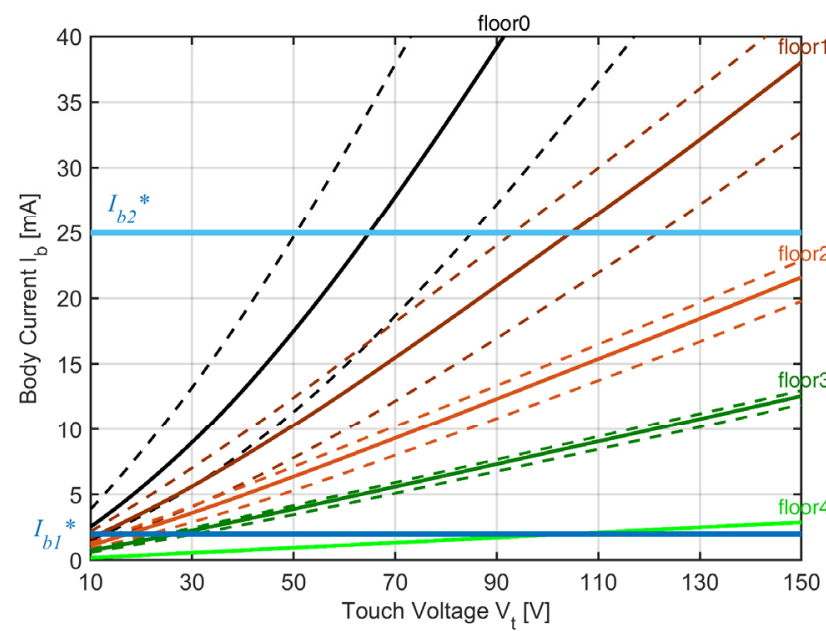

(a)

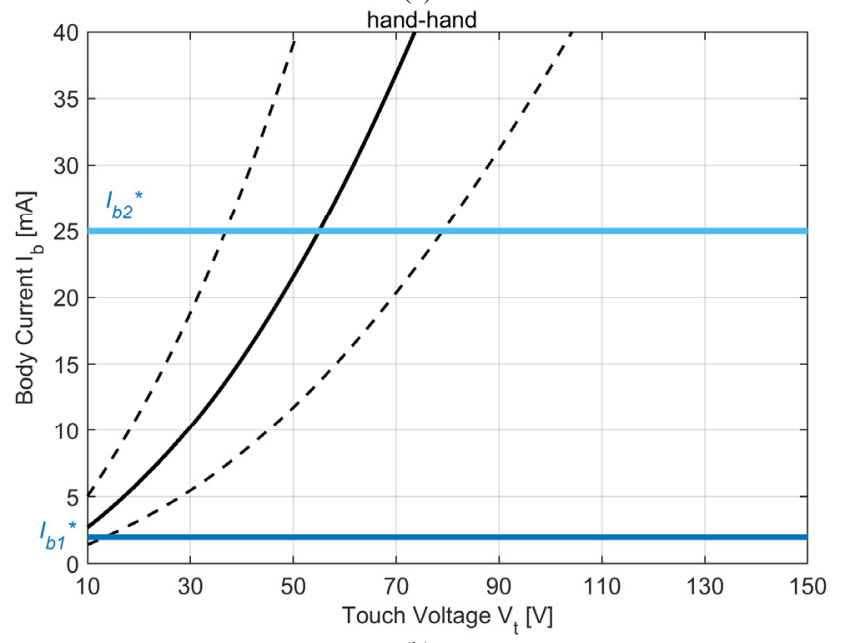

(b)

Fig. 3. Touch voltage and insulation limits to comply with $I_{b 1}{ }^{*}$ and $I_{b 2}{ }^{*}$ : (a) hand-to-feet scenario, (b) hand-to-hand scenario between conductive parts (wall already considered as floor for hand-to-feet).

\section{TRACTION CIRCUIT AND TRACTION POWER SIMULATION}

The traction return circuit is composed of tracks, TPS negative cables and other track bonding cables. Cross bonding is used between running rails to improve track balancing and between tracks to reduce the return circuit resistance and allow regenerated power exchange between trains on different tracks. Tracks are subject to a fluctuating potential caused by the variable flow of return current back to TPSs. The return circuit is sized to reduce such voltage drop to an acceptable level to increase the useful voltage for the trains, at the same time reducing touch voltage and stray current values.

Track voltage values for main line and stations are made compliant with the semi-permanent voltage limit $\mathrm{V}_{\text {perm }}$ of $120-150 \mathrm{~V}$ (the latter corresponding to a duration of $300 \mathrm{~s}$ ) [4]. Voltage Limiting Devices (VLDs, named "negative grounding devices" by the IEEE 1653.3 [16]) are installed at each TPS, short circuiting the negative terminal (and the track connected to it) to station earth in case of excessive voltage. The VLD can implement amplitude-time limit curves or just a hard threshold. The impact on stray current is negligible, not only because current leaves the track to the earth for very short time intervals, but also because such track current flows in a main earthing circuit and not through reinforcement and metal works. If the distance and difference of potential to the nearest TPS are significant, a VLD should be installed at each station (discharging onto the station earth circuit) protecting directly the track section where PSDs are located.

During design and construction information for electrical safety verification against limits of sec. II comes from traction power simulations. Despite the general agreement on train weight and suitable dynamic profiles, selection of maximum contractual headway, and inclusion of degraded modes with out-of-service TPSs, the time-space granularity of results and the electrical parameters values are much less regulated. The IEEE Std. 1653.3 [16] requires a sample time of 0.1 to $5 \mathrm{~s}$ and the use of schedule offset.

The rail longitudinal resistance $R_{r}$ may vary between samples [33] and also with temperature and wearing (cross section reduction is usually assigned a $-10 \%$ worst case at the end of service life). Rail welding points may also increase the longitudinal resistance (up to $5 \%$, as allowed by IEC 62128-2). Correspondingly the track-to-earth voltage $V_{t e}$ varies and consequently the useful voltage at the current collection point: the $(10+5) \%$ figure applied to a $60 \mathrm{~kg} / \mathrm{m}$ rail [33] adds $2.4 \mathrm{~V}$ to the mean $16 \mathrm{~V} / \mathrm{km}$ of voltage drop per $1 \mathrm{kA}$ of return current. A temperature difference of $25^{\circ} \mathrm{C}$ may cause another $10 \%$ change.

Track insulation differs with construction techniques and varies with aging and environmental conditions. When assigning $R_{t e}$, it should be considered that a low $R_{t e}$ implies larger stray current leakage, but at the same time a slightly lower $V_{t e}$. So to formally maximize $V_{t e}$ the highest $R_{t e}$ possible should be used, i.e. using values for new tracks or very clean systems [27]. The assessment of stray current and track insulation should be focused instead on aged and polluted scenarios, when $R_{t e}$ approaches the limit values of IEC 62128-2. The IEEE Std. 1653.3, Table C.1, gives a complete list of $R_{t e}$ values from new systems with direct fixation $(300-450 \Omega / \mathrm{km})$ to wet tracks $(0.6-3 \Omega / \mathrm{km})$. Recent contracts converge to intermediate values, namely 50-150 $\Omega / \mathrm{km}$ for new tracks to test during test $\&$ commissioning.

For touch voltage risk assessment $V_{t e}$ values measured vs. time and chainage should be available. Often $V_{t e}$ results are instead limited to one maximum for each line section, only for the purpose of demonstrating compliance to $\mathrm{V}_{\text {perm }}$.

\section{SCENARIOS, DESIGN OPTIONS AND SOLUTIONS}

The examined scenarios regard the electrical safety risks to which the passengers are exposed when interfacing with the track. Provisions for stray current protection represent additional design constraints.

\section{A. Electrical safety scenarios}

The electrical safety scenarios that will be considered in the following and that are typical of the safety assessment are:

$\mathbf{S}_{\mathrm{d}-\mathrm{v}}$ : a passenger enters or leaves the train touching parts at different potential located on the train and the PSD; the contact may occur with foot or hand (please note that step 
voltages are not considered being step voltage limits always larger than those of touch voltage).

$\mathbf{S}_{\mathbf{p}-\mathrm{v}}$ : a passenger enters or leaves the train touching parts at different potential located on the train and on the station platform; the contact may occur with foot or hand.

$\mathbf{S}_{\mathbf{p - d}}$ : a passenger stands on the platform and touches parts at different potential on the PSD and on the station platform (including floors, walls, metal works and equipment).

$\mathbf{S}_{\mathbf{c - d}}$ : the catenary or derailed pantograph touches the PSD for an indefinite interval of time.

\section{B. Analysis and discussion of design choices}

Generally speaking the PSD is either electrically insulated from station earth or in contact with it (e.g. touching ironmongery, conductive path due to internal stagnation, etc. preventing a sufficient and durable insulation).

\section{1) PSD bonded to the track potential}

An electrically insulated PSD may be bonded to the track, in order to avoid any difference of potential with the train body (solving $\mathrm{S}_{\mathrm{d}-\mathrm{v}}$ ). The contact with the train body from platform $\left(\mathrm{S}_{\mathrm{p}-\mathrm{v}}\right)$ is less likely, either through an open PSD or stretching over a half-height PSD.

The problem is then transferred to the interface with the platform $\left(\mathrm{S}_{\mathrm{p}-\mathrm{d}}\right)$ : the necessary platform insulation level was discussed in sec. II.D and must limit the body current as per sec. II.E. For $\mathrm{S}_{\mathrm{p}-\mathrm{d}}$ insulation may be applied to platform floor and walls (for a typical extension of $2.5 \mathrm{~m}$, including reachable conductive parts) or to the PSD.

Platform and walls must be covered with insulating material (e.g. tiles, plaster or a coating), avoiding metal cladding, unless fully insulated from the structure. Equipment (such as the display or A and B in Fig. 1) and metal parts (e.g. handrails, manholes in the floor and doors) within $2.5 \mathrm{~m}$ also must be insulated from earth, going against local codes, although some types of equipment may be provided of the Class II type (doubly or reinforced insulated), or unearthed because supplied at low safe voltage or with limited energy (Class III).

The PSD Alu frame is always anodized and thus insulated, yet with potential issues of durability and periodic verification. However, small metallic parts (such as door locks, hinges, etc.) cannot be insulated, but they represent a small surface, leading to a lower body current, since the associated body resistance is 4 to 40 times larger, as observed at the end of sec. II.B.2). Such solution that would put protection at the source is never considered, possibly oriented by the IEC 60364-4-41 floor/wall insulation requirement, which regards nevertheless live parts at a higher voltage. It must be noted that loss of insulation of the PSD coating would never be detected until a person touches it. A leakage current monitor (LCM) installed on the track bonding conductors may be set to issue an alarm, or at the upper threshold to react by triggering the track VLD, supposing a direct contact with body current flow. This at some extent assigns a safety function to the LCM.

Being the PSD also exposed to traction faults, bonding is achieved by means of a conductor sized for the expected fault current $\left(\mathrm{S}_{\mathrm{c}-\mathrm{d}}\right)$, usually implemented as $2 \times 70$ up to $2 \times 120$ $\mathrm{mm}^{2}$.

\section{2) PSD bonded to the station earth}

If the PSD cannot be insulated effectively from station earth when bonded to the track, then it should be bonded to a suitable point of the station earthing system (with respect to $\mathrm{S}_{\mathrm{c}-\mathrm{d}}$ ). Removing the bonding to the track prevents stray current flow and removes the source of risk for people at platform. The relevant scenario is now $S_{d-v}$, rather than $S_{p-d}$, and the solution is again the insulation of the accessible parts of the PSD. It should be considered that passenger's contact between vehicle and PSD is a matter of seconds when boarding or leaving the train, whereas the contact between platform and PSD may occur for a longer time while waiting the next train (e.g. leaning on the PSD or touching it for curiosity are more likely to occur and relevant for probabilistic risk assessment).

\section{3) Monitoring the PSD leakage current}

The degradation of the PSD insulation from station earth for design solutions with PSD bonded to the track is usually tackled by the LCM. With thresholds of some to tens of $\mathrm{mA}$ they can suitably detect a drop of PSD insulation from station earth. The LCM may raise an alarm, or even triggering the track VLD. Its possible use as protective device was cogitated above in IV.B.2.

4) PSD selective bonding to the track and use of VLDs

The most relevant points of the previously analyzed scenarios may be synthesized as:

- the PSD cannot be left floating, so to clear a traction fault by the TPS circuit breaker $\left(\mathrm{S}_{\mathrm{c}-\mathrm{d}}\right)$;

- the PSD must be insulated from the station earth for stray current protection, when bonded to the track; conversely, it can be connected to station earth if isolated from the track, leaving a residual risk for the vehicle-PSD interface $\left(\mathrm{S}_{\mathrm{p}-\mathrm{v}}\right)$;

- for touch voltage protection the platform must be insulated for IAE width of $2.5 \mathrm{~m}$ when the PSD is at track potential.

An improved solution seems the removal of excessive track voltage (addressing $\mathrm{S}_{\mathrm{p}-\mathrm{d}}$ ), leaving the PSD bonded to the track (solving $\mathrm{S}_{\mathrm{p}-\mathrm{v}}$ and $\mathrm{S}_{\mathrm{c}-\mathrm{d}}$ ). This can be achieved by a VLD-O (as defined in IEC 62128-1, sec F.2), shunting the track to earth, shaving the largest track voltage values. This, reduces also the flow of stray current through the PSD. An analysis of the impact of the feeding scheme and the exchange of current between trains was carried out in [34], where the VLD thresholds were: $U>=92 \mathrm{~V}$ (delay of $0.1 \mathrm{~s}$, switch off after $10 \mathrm{~s}$ ), $\mathrm{U}>>=150 \mathrm{~V}$ (no delay, switch of after $10 \mathrm{~s}$ ), and $\mathrm{U}>>>=600 \mathrm{~V}$ (no delay, switch off with reset command). These three thresholds represent a cautious limit anticipating $\mathrm{V}_{\text {perm }}$, the $\mathrm{V}_{\text {perm }}$ limit for duration up to $300 \mathrm{~s}$, and protection against short circuit (the traction voltage was $1500 \mathrm{Vdc}$ ).

The lower the VLD threshold, the lesser is the impact on electrical safety, but the larger the percentage of time that the track is shunted to earth. This is not stray current leakage as such, since the VLD current is conveyed through a properly sized conductor directly to the main station earth, but the current intensity is quite large and such arrangement should be used for extreme cases, and not as an ordinary means of PSD voltage reduction.

A better and novel solution is the insertion of a VLD in 
series with the PSD-track connection: the PSD is normally electrically isolated, but protected against a traction fault (through the triggered VLD). Two points need to be assessed: VLD leakage current and its short-circuit capability.

- The VLD when isolated must ensure a low leakage current below $I_{b 1}{ }^{*}(2 \mathrm{~mA})$. Although the normative limit [35] is 5 or $50 \mathrm{~mA}$ as per VLD class, modern VLDs perform better, as shown in Table $\mathrm{V}$ (commercial devices are listed for demonstration without intention of endorsement).

- Traction fault current varies with the position of the short circuit along the line; near the TPS the intensity is maximum but is also cleared more rapidly (usually 15-40 $\mathrm{ms}$, roughly inversely proportional to intensity).

As in Table $\mathrm{V}$ current levels in the range 5-10 kA are recoverable (operating more than once), with Saltek device performing better as for intensity and time duration. The voltage threshold cannot be too low because otherwise the VLD would short the PSD to the track continuously, exposing passengers to the same situation when PSD is solidly bonded. Since track voltage is ordinarily limited to $120 \mathrm{~V}$ or less for compliance to $\mathrm{V}_{\text {perm }}$ by means of VLD-O at TPS (see thresholds use in Guangzhou Metro Line 8 analyzed in [34]), a slightly larger threshold may be selected so that the PSD keeps isolated for all normal operating conditions.

\begin{tabular}{|c|c|c|c|c|}
\hline & \multicolumn{4}{|c|}{ TABLE V. EXAMPLES OF VLDS } \\
\hline & \begin{tabular}{|l|} 
Thr. \\
volt.
\end{tabular} & $\begin{array}{c}\text { Recov. } \\
\text { short circ. }\end{array}$ & $\begin{array}{l}\text { Non-recov. } \\
\text { short circ. }\end{array}$ & $\begin{array}{l}\text { Leakage } \\
\text { current }\end{array}$ \\
\hline $\begin{array}{l}\text { ABB (VLD O+F) } \\
\text { HVL } 120-0.3^{(1)}\end{array}$ & $120 \mathrm{~V}$ & $\begin{array}{c}6.7 \mathrm{kA}-12 \mathrm{~ms} \\
4.7 \mathrm{kA}-23 \mathrm{~ms} \\
2.1 \mathrm{kA}-100 \mathrm{~ms}\end{array}$ & $\begin{array}{c}45 \mathrm{kA}-50 \mathrm{~ms} \\
20 \mathrm{kA}-100 \mathrm{~ms}\end{array}$ & $0.2 \mathrm{~mA}$ \\
\hline $\begin{array}{l}\text { Saltek (VLD O+F) } \\
\text { BVL-50-120-R01 }{ }^{(2)}\end{array}$ & $120 \mathrm{~V}$ & $\begin{array}{c}15 \mathrm{kA}-50 \mathrm{~ms} \\
10.6 \mathrm{kA}-100 \mathrm{~ms}\end{array}$ & 一 & $0.12 \mathrm{~mA}$ \\
\hline Hakel HL-120 & $120 \mathrm{~V}$ & $4.7 \mathrm{kA}-23 \mathrm{~ms}$ & $20 \mathrm{kA}-100 \mathrm{~ms}$ & - \\
\hline
\end{tabular}

(1) library.e.abb.com/public/9a224f476b719872c1257b130057b31d/HVL (e).pdf

(2) www.saltek.eu/en/vyrobky/vld-omezovace-napeti

(3) www.hakel.com/news/low-voltage-limiter-hl120-hakel-surge-protector

\section{5) General reduction of track voltage}

Track voltage may also be reduced (rather than hard limited) by adopting innovative solutions that redesign the traction supply and return. Benefits are in two directions, namely reduction of stray current and limitation of touch voltage [36][37]. The deployment of compensating devices (named DC AutoTransformer, DCAT, in [37]) can be targeted to existing systems where the largest track voltages have been observed, thus leveling out the track voltage profile to values that guarantee compliance to body current limits also for limited values of floor and PSD insulation.

A more traditional method, such as using parallel return cables, would require $1000 \mathrm{~mm}^{2}$ of copper conductors per track to attain a reduction of track voltage by a factor of 2 .

\section{CONCLUSIONS}

This work has considered the problem of electrical safety for the platform of dc railways and rapid transit systems, focusing in particular on the PSD interface. Standard requirements have been discussed to avoid over-specification and achieve the objective of minimizing impact on passengers (and staff) to safe and acceptable levels. Stray current limitation was also jointly considered when discussing technical solutions and design choices. The outcome of sec. II is a set of touch voltage, body current and body resistance values to use for the electrical safety assessment.

Starting from the evaluation of touch voltage and body current exposure in selected electrical safety scenarios, various solutions have been considered, from the insulation of parts and surfaces, to the selection of the reference potential for PSD bonding, to the limitation of track voltage and the limitation of current transferred through PSD bonding. The latter in particular is not known to be proposed before and represents an improvement of existing solutions with a minimum impact in terms of cost and required space and modifications.

\section{REFERENCES}

[1] Hyundai, "Platform Screen Door," March 2014 (online: hyundaielevator.co.ir/adfiles/Download_cat/hyundai-cat_3023086.pdf, last access Sept. 15, 2020)

[2] W.M. Sim, M. Thong, C.F. Chan, "Touch Voltage Protection on Singapore MRT System,” Proc. of Intern. Pow. Eng. Conf., Nov. 29 Dec. 2, 2005, Singapore.

[3] X.M. Huang and H.H. Chen, "Design of DC Operating Power for Metro Platform Screen Doors," Proc. of Intern. Conf. on Intell. Sys. Design and Eng. App., Oct. 13-14, 2010, Changsha, China.

[4] IEC 62128-1, Railway applications - Fixed installations - Electrical safety, earthing and the return circuit - Part 1: Protective provisions against electric shock, 2011.

[5] IEC 60364-4-41, Low-voltage electrical installations - Part 4-41: Protection for safety - Protection against electric shock, 2005.

[6] IEC 62128-2, Railway applications - Fixed installations - Electrical safety, earthing and the return circuit - Part 2: Provisions against the effects of stray currents caused by d.c. traction systems, 2013.

[7] JICA Preparatory Survey on Greater Cairo Metro Line 4, Final Report - Vol. 3, sec. 4.10.4; online https://openjicareport.jica.go.jp/pdf/ 12001715_07.pdf (last access July 16, 2020)

[8] J. Birbeck et al., "Engineering Design of Platform Screen Doors for Crossrail's Mined Stations," 2018, online https://learninglegacy.crossrail.co.uk/documents/engineering-designplatform-edge-screens-crossrails-mined-stations/ (last access July 16, 2020)

[9] Metro Manila Subway Project Phase 1 - Package CP106: E\&M Systems and Track Works - Part2: Employer's Requirements - 7 Platform Screen Door (PSD) at Stations, Dec. 2019; online http://psphilgeps.gov.ph/home/images/BAC/ForeignAssitedProjects/2019/PHP267/ CP106/07\%20PSD_12\%20Dec\%202019\%20(PA).pdf (last access July 16, 2020)

[10] J.-D. Park, "Ground Fault Detection and Location for Ungrounded DC Traction Power Systems," IEEE Trans. Veh. Techn., Vol. 64, No. 12, pp. 5667-5676, Dec. 2015.

[11] E. Pons, R. Tommasini, and P. Colella, "Fault Current Detection and Dangerous Voltages in DC Urban Rail Traction Systems," IEEE Trans. Ind. Appl., Vol. 53, No. 4, pp. 4109-4115, July-Aug. 2017.

[12] J. Tian et al., "Analysis of Rail Potential with the Influence of Multinode Power Distribution in Urban Rail Power Supply System," 45th Ann. Conf. of IEEE Ind. Electron. Soc. (IECON), Oct. 14-17, 2019, Lisbon, Portugal.

[13] G. Du et al., "Effect of Crossing Power Restraint on Reflux Safety Parameters in Multitrain Subway Systems," IEEE Trans. Transp. Electrif., Vol. 5, No. 2, pp. 490-501, June 2019.

[14] IEC 60364-4-41, Low-voltage electrical installations - Part 4-41: Protection for safety - Protection against electric shock, 2005.

[15] C.-H. Lee and P. S. Meliopoulos, "A Comparison of IEC 479-1 and IEEE Std 80 on Grounding Safety Criteria," Proc. Natl. Sci. Counc. ROC (A), Vol. 23, No. 5, pp. 612-621, 1999.

[16] IEEE Std. 1653.3, IEEE Guide for Rail Transit Traction Power Systems Modeling, 2012. 
[17] OSHA 1910.303, Occupational Safety and Health Standard, online https://www.osha.gov/laws-

regs/regulations/standardnumber/1910/1910.303 (last access July 17, 2020)

[18] OSHA, Standard Interpretation 1910.303(g)(2)(i), online https://www.osha.gov/laws-regs/standardinterpretations/2015-09-04 (last access July 17, 2020)

[19] IEC 61140, Protection against electric shock - Common aspects for installation and equipment, 2016.

[20] IEC 60479-1, Effects of current on human beings and livestock - Part 1: General aspects, 2018.

[21] D. Dechent et al., "Direct current electrical injuries: A systematic review of case reports and case series," Burns, Vol. 46, pp. 267-278, 2020.

[22] A. M. Baruchin, "Circumferential Electric Burns of the Ring Finger," Annals of the MBC, Vol. 5, No. 1, March 1992.

[23] IEC 60364-6, Low voltage electrical installations - Part 6: Verification, 2016.

[24] IEC/TR 60479-5, Effects of current on human beings and livestockPart 5: Touch voltage threshold values for physiological effects, 2007.

[25] E. W. Kimbark, Direct Current Transmission, J. Wiley, 1971.

[26] F. Filippone, A. Mariscotti, and P. Pozzobon, "The Internal Impedance of Traction Rails for DC Railways in the 1-100 kHz Frequency Range”, IEEE Trans. Instrum. Meas., Vol. 55, No. 5, pp. 1616-1619, Oct. 2006.

[27] A. Mariscotti and P. Pozzobon, "Experimental results on low rail-torail conductance values", IEEE Trans. Veh. Techn., Vol. 54, No. 3, pp. 1219-1222, May 2005.

[28] G. Lucca, "Evaluation of Rail Conductances," Ingegn. Ferroviaria, Vol. 12, pp. 935-949, Dec. 2017

[29] L. Ivanek, V. Mostyn, K. Schee, and J. Grun, "The Sensitivity of the Input Impedance Parameters of Track Circuits to Changes in the Parameters of the Track," Adv. Electr. Electron. Eng., Vol. 15, No. 1, pp. 77-83, 2017.

[30] IEC 60479-2, Effects of current on human beings and livestock - Part 2: Special aspects, 2019.

[31] IEC 60990, Methods of measurement of touch current and protective conductor current, 2016.

[32] D. Signorino et al., "Dataset of measured and commented pantograph electric arcs in DC railways," Data In Brief, Vol. 31, id 105978, 2020

[33] A. Mariscotti, "Impact of Rail Impedance Intrinsic Variability on Railway System Operation, EMC and Safety," Int. J. Electr. Comput. Eng. (IJECE), Vol. 11, No. 1, pp. 17-26, Feb. 2021.

[34] G. Du, C. Wang, J. Liu, G. Li, and D. Zhang, "Effect of Over Zone Feeding on Rail Potential and Stray Current in DC Mass Transit System," Math. Probl. Eng., 2016, id 6304726, pp. 1-15.

[35] EN 50526-2, Railway applications - Fixed installations - D.C. surge arresters and voltage limiting devices - Part 2: Voltage limiting devices, 2014.

[36] J. Gu, X. Yang, T. Q. Zheng, Z. Shang, Z. Zhao, and W. Guo, "Negative Resistance Converter Traction Power System for Reducing Rail Potential and Stray Current in the Urban Rail Transit," IEEE Trans. Transp. Electrif., 2020, in print.

[37] M. Wang, X. Yang, T. Q. Zheng, and M. Ni, "DC AutotransformerBased Traction Power Supply for Urban Transit Rail Potential and Stray Current Mitigation," IEEE Trans. Transp. Electrif., Vol. 6, No. 2, pp. 762-773, June 2020. 